\title{
The Role of Dapagliflozin in the Management of Heart Failure: An Update on the Emerging Evidence
}

\author{
Manasvi Gupta' \\ Shiavax Rao $\mathbb{D D}^{2}$ \\ Gaurav Manek' \\ Gregg C Fonarow $\mathbb{D}^{3}$ \\ Raktim K Ghosh ${ }^{4}$ \\ 'Department of Internal Medicine, \\ University of Connecticut, Hartford, CT, \\ USA; ${ }^{2}$ Department of Medicine, MedStar \\ Union Memorial Hospital, Baltimore, MD, \\ USA; ${ }^{3}$ Department of Medicine, Ronald \\ Reagan UCLA Medical Center, Los \\ Angeles, CA, USA; ${ }^{4}$ MedStar Heart and \\ Vascular Institute, Union Memorial \\ Hospital, Baltimore, MD, USA
}

\begin{abstract}
The burden and cost of heart failure management, primarily in the form of hospitalization in the setting of decompensated heart failure, continue to be some of the biggest clinical challenges in cardiovascular medicine. In recently published randomized controlled trials, including DAPA-HF, sodium-glucose cotransporter 2 (SGLT2) inhibitor dapagliflozin was shown to reduce hospitalization from heart failure or mortality associated with cardiovascular causes, when added to existing guideline-directed medical therapy. The American College of Cardiology (ACC) released a Clinical Pathway guideline that recommends the use of dapagliflozin in clinical management of heart failure, with or without diabetes. Furthermore, the results of the DAPA-CKD trial broaden the utility of dapagliflozin as a therapeutic option in patients with advanced kidney disease. In this article, the authors explore the existing evidence on dapagliflozin in heart failure with reduced ejection fraction and highlight the need for further research on uses of dapagliflozin in the world of heart failure.
\end{abstract}

Keywords: dapagliflozin, DAPA-HF, DECLARE-TIMI, DEFINE-HF, HFrEF, DAPA-CKD

\section{Introduction}

The worldwide burden of heart failure (HF) has been estimated to be upwards of 23 million individuals. In the United States (US) alone, an estimated 6 million adults are affected by HF, with close to 1 million hospitalizations with a primary discharge diagnosis of HF annually. Approximately $50 \%$ of these cases can be attributed to HF with reduced ejection fraction (HFrEF), referring to a left ventricular ejection fraction (LVEF) of $40 \%$ or less. ${ }^{1,2}$ Traditionally, guideline-directed medical therapy (GDMT) for HFrEF has been focused on inhibition of the reninangiotensin-aldosterone system, neprilysin and sympathetic pathways through agents including angiotensin-converting enzyme (ACE) inhibitors, angiotensin II receptor blockers (ARB), angiotensin receptor-neprilysin inhibitors (ARNI), beta blockers (BB) and mineralocorticoid receptor antagonists (MRA). ${ }^{3}$ More recently, sodium-glucose cotransporter 2 (SGLT2) inhibitors have shown further reductions in heart failure hospitalization (HHF), cardiovascular (CV) events and mortality, especially for HFrEF patients. Initial SGLT2 inhibitor trials focused on improvement in glycemic control in diabetics, with CV outcomes explored only as secondary endpoints. Subsequent randomized trials of SGLT2 inhibitors (based on empagliflozin and dapagliflozin), including the EMPEROR-Reduced and DAPA$\mathrm{HF}$ trials, were designed to evaluate $\mathrm{CV}$ outcomes and reported reductions in $\mathrm{CV}$ events (particularly HHF) in HFrEF (with or without diabetes). ${ }^{4,5}$ In the light of
Correspondence: Raktim K Ghosh

$\mathrm{Tel}+\mathrm{I}$ 4I0-366-5600

$\mathrm{Fax}+1$ 410-889-4952

Email raktimghoshmd@gmail.com 
these landmark trials, the American College of Cardiology (ACC) recently released the 2020 Expert Consensus Decision Pathway on Novel Therapies for Cardiovascular Risk Reduction in Patients with Type 2 Diabetes, which is specific for HFrEF and calls for use of SGLT2 inhibitors (including dapagliflozin) in HFrEF with or without diabetes mellitus (DM). ${ }^{6}$ In this review article, the authors review the evidence on dapagliflozin in HF, including existing literature and ongoing trials, and the role of this drug in the clinical management of HF.

\section{Pharmacology of SGLT2 Inhibitors, in Particular Dapagliflozin}

Sodium-glucose cotransporter 2 is responsible for reabsorption of approximately $90 \%$ of the urinary glucose in the proximal tubule of the nephron. Inhibition of SGLT2 induces glucosuria, which is more pronounced in hyperglycemic individuals owing to the higher amounts of glucose filtered into the urine. The effect of glucosuria diminishes with normalizing of blood glucose levels. ${ }^{7}$ Among individuals with HFrEF, with or without DM, the addition of dapagliflozin has been associated with decreased rates of $\mathrm{CV}$ death or worsening HF, as well as all-cause mortality. ${ }^{5}$ In addition to lowering blood glucose, SGLT2 inhibitors such as dapagliflozin also enhance natriuresis, change tissue sodium handling, lower systolic blood pressure and reduce body mass. ${ }^{8,9}$ Early decreases in systolic blood pressure, weight and estimated glomerular filtration rate (eGFR), as well as increase in hematocrit are consistent with a diuretic action. ${ }^{10}$ According to the established side effect profile, dapagliflozin is associated with significantly higher rates of urinary tract infections (4.3\% vs $3.7 \%)$, urinary urgency, frequency, and genital mycotic infections in females $(6.9 \%$ vs $1.5 \%)$ and in males $(2.7 \%$ vs $0.3 \%) .{ }^{11}$

\section{Molecular Mechanisms of Dapagliflozin}

Regarding outcomes relating to $\mathrm{CV}$ benefit, specific mechanisms have not been fully elucidated, but several putative mechanisms have been proposed. Among these are reduction in preload and afterload (resulting in improvement in ventricular loading), improvement in myocardial metabolism and alterations of cardiac fibrosis. ${ }^{9,12}$ SGLT2 inhibitors have been shown to inhibit the sodium proton channel (NHE) in the cardiac myocytes that eventually leads to the reduction in intracellular
Table I Non Glycemic Mechanisms of SGLT2 Inhibitors

\begin{tabular}{|l|l|}
\hline Renal effects & $\begin{array}{l}\text { Reduction in albuminuria } \\
\text { Reduction in tubular inflammation due to lower } \\
\text { RAAS activation } \\
\text { Reduction in intraglomerular pressure and tubular } \\
\text { hypertrophy }\end{array}$ \\
\hline $\begin{array}{l}\text { Cardiovascular } \\
\text { effects }\end{array}$ & $\begin{array}{l}\text { Weight loss } \\
\text { BP reduction } \\
\text { Decrease in epicardial fat thickness - empagliflozin } \\
\text { Reduction in the serum uric acid } \\
\text { Favorable effect on the lipid profile } \\
\text { Lesser surges of insulin secondary to hypoglycemia } \\
\text { as the glycemic actions of the class are non-insulin } \\
\text { dependent }\end{array}$ \\
\hline
\end{tabular}

calcium and mitochondria-induced cellular damage that lies at the heart of myocardial remodeling. ${ }^{13,14}$

At the level of the kidneys, in addition to glucosuria by direct inhibition of glucose reabsorption in the proximal convoluted tubules, the SGLT2 inhibitors have also been demonstrated to have anti-inflammatory activity in animal models. ${ }^{15}$ The blockade of SGLT2 channels causes a decrease in intraglomerular pressure and subsequently decreases in glomerular filtration and tubular hypertrophy. This consequence is further amplified by afferent vasoconstriction mediated by direct action. ${ }^{16}$ The cardioprotective and renoprotective actions of SGLT2 inhibitors are summarized in Table $1 .^{17}$

\section{Existing Literature on Role of Dapagliflozin in Cardiorenal Disease}

In the first of the series of trials focused on the role of dapagliflozin in CV diseases, the DECLARE-TIMI 58 trial studied 17,160 patients with type $2 \mathrm{DM}$. The trial found that the use of dapagliflozin resulted in lower rates of CV death and a reduction in HHF, with the number needed to treat calculated at 111. The reduction in HHF was added in the post hoc analysis and the trial was not powered for these outcomes. The trial did not show any statistically significant difference with regards to reduction in major adverse CV events. ${ }^{18}$ Subsequently, 263 patients with HFrEF (NYHA functional class II-III), and elevated natriuretic peptides were studied in the DEFINE-HF trial. The trial did not find any significant difference in the levels of NT-proBNP in patients receiving dapagliflozin versus placebo. However, there was an increased proportion of patients experiencing clinically meaningful 
improvements in HF related health status measured in terms of the Kansas City Cardiomyopathy Questionnaire or KCCQ (number needed to treat of 7-10). ${ }^{19}$ This trial was effective in demonstrating the safety of dapagliflozin in patients without type 2 DM. The DAPA-HF trial studied a larger group of patients with similar characteristics (4744 patients with HFrEF, NYHA class II-IV) with and without DM. The investigators of this landmark trial found a significant reduction in the primary endpoint of worsening $\mathrm{HF}$ or death from CV causes in the dapagliflozin group compared with the placebo group, irrespective of presence of DM. The secondary outcome of the trial included a change in KCCQ at the end of 8 months, compared with baseline, which was also found to improve with dapagliflozin. ${ }^{5}$ When stratified according to the baseline score, exploratory analysis revealed improvement with dapagliflozin compared with placebo across the entire range of baseline KCCQ score. ${ }^{20} 71 \%$ of patients in the enrolled population in the DAPA-HF trial were taking MRA and an exploratory analysis of the trial data revealed similar results in the population with MRA compared with the population without MRA (HR 0.74; 95\% CI 0.63-0.87 versus HR $0.74 ; 95 \%$ CI $0.57-0.95$, respectively, for the primary combined endpoint of $\mathrm{HF}$ exacerbation or $\mathrm{CV}$ death). ${ }^{21} 10.7 \%$ of patients in the DAPA-HF cohort were on the sacubitril/valsartan combination, and were found to have similar outcomes in terms of primary endpoints of efficacy and safety with add-on of dapagliflozin, when compared with the remaining population that did not receive the sacubitril/valsartan combination, supporting the safe use of the drug in addition to GDMT. ${ }^{22}$ The absolute risk reduction of the primary endpoint was also seen to be greatest in the subgroup that had a history of recent hospitalization (defined as within 12 months of randomization) from $\mathrm{HF}$ worsening (ARR 9.9\%, 95\% CI $3.3-16.5 \%$ compared with groups with hospitalization prior to the 12 month period of before randomization). ${ }^{23}$ In another interesting post hoc analysis of the DAPA-HF trial, similar results in terms of efficacy and safety with dapagliflozin in ischemic and non-ischemic cardiomyopathy were noted. The incidence of objective parameters such as HHF and mortality were found to be similar in both groups (HR 0.77 [0.65-0.92] and HR 0.71 [0.580.87 , respectively; $p$ for interaction $=0.55$ ) and the comparability of both the groups extended to qualitative measures such as improvement in functional status (measured using KCCQ). ${ }^{24}$ Lastly, no difference was noted in benefits seen with the drug between men and women in the enrolled group. ${ }^{24}$ The details of the trials are summarized in Table 2. Following the publication of the game changing DAPA-HF trials, multiple systemic analysis have confirmed dapagliflozin to be more effective than placebo in reducing $\mathrm{HHF}$ and $\mathrm{CV}$ death, in patients both with and without DM. ${ }^{25-28}$

In another recently published landmark trial (DAPACKD), the population with eGFR as low as $25 \mathrm{~mL} / \mathrm{min} /$ $1.73 \mathrm{~m}^{2}$ was shown to have improved $\mathrm{CV}$ outcomes and HHF with dapagliflozin, compared with placebo, which expands the usability of dapagliflozin in this unique population. $^{29}$

Even though efficacy related data support the addition of dapagliflozin to GDMT in HFrEF, the practical use may be limited by the additional cost of the drug. In a study based out of the United Kingdom by McEwan et al., the treatment with dapagliflozin was noted to reduce the lifetime cost by $£ 2552$ in patients with type II DM for major adverse $\mathrm{CV}$ events. ${ }^{30}$ Similar favorable cost-benefit ratios were seen in studies based on Australian and Thai healthcare systems. ${ }^{31,32}$ In a study performed on data extrapolated to the American healthcare system, it was found that the addition of dapagliflozin to GDMT was beneficial in terms of long term cost-benefit ratios, possibly in both diabetic and non-diabetic populations. ${ }^{33}$

\section{Ongoing Trials on Dapagliflozin in Heart Failure}

In an interesting analysis performed by Maltês et al. aimed at evaluating the generalizability of the results of the DAPA-HF trial, it was noted that the limiting factors to widespread use of dapagliflozin remained the lack of literature regarding efficacy in patients with advanced chronic kidney disease (CKD), defined as eGFR $<25 \mathrm{~mL} / \mathrm{min} / 1.73 \mathrm{~m}^{2}$, and LVEF $>40 \%{ }^{34}$ Thus, the ongoing trials are focused on bridging this gap. In addition to evaluating the role of dapagliflozin in these patients with advanced $\mathrm{CKD}$ and HF with preserved ejection fraction (HFpEF), there is also ongoing research focusing on patients with acute decompensated HF. The DICTATE-HF trial is currently recruiting patients presenting to the hospital with decompensated HF requiring intravenous diuretics to evaluate the change in the weight seen with the addition of dapagliflozin to standard diuretic regimen. The inclusion criteria include patients across all ejection fractions but with established DM (NCT04298229). There are two major trials focused on HFpEF that are currently 
Table 2 Summary of Major Clinical Trials on Dapagliflozin in Heart Failure

\begin{tabular}{|c|c|c|c|c|}
\hline $\begin{array}{l}\text { Trial Name } \\
\text { (Year of } \\
\text { Publication) }\end{array}$ & $\begin{array}{l}\text { Sample Size, } \\
\text { Trial Design and } \\
\text { Follow-Up } \\
\text { Period }\end{array}$ & Sample Population & Primary \& Secondary Outcomes & Results \\
\hline $\begin{array}{l}\text { DAPA-HF } \\
(2019)^{5}\end{array}$ & $\begin{array}{l}4744 \\
\text { Randomized, } \\
\text { double-blind, } \\
\text { placebo-controlled } \\
\text { Phase } 3 \text { trial } \\
\text { Median follow up } \\
\text { 18.2 months }\end{array}$ & $\begin{array}{l}\text { Adults, } \geq 18 \text { years } \\
\text { Symptomatic HFrEF (NYHA class II- } \\
\text { IV), LVEF } \leq 40 \% \text {, elevated NT-proBNP, } \\
\text { eGFR } \geq 30 \mathrm{~mL} / \mathrm{min} / 1.73 \mathrm{~m}^{2} \text { (CKD-EPI } \\
\text { formula) on GDMT }\end{array}$ & $\begin{array}{l}\text { Primary outcome: } \\
\text { Composite of worsening heart failure or } \\
\text { death from cardiovascular causes. } \\
\text { Secondary Outcome: } \\
\text { Composite of hospitalization for heart } \\
\text { failure or cardiovascular death. }\end{array}$ & $\begin{array}{l}\text { Primary outcome and secondary } \\
\text { outcomes were significantly lower in the } \\
\text { dapagliflozin group compared with } \\
\text { placebo (HR } 0.74 ; 95 \% \mathrm{Cl} 0.65-0.85 \text {; } \\
\mathrm{P}<0.00 \mathrm{I} \text { and } \mathrm{HR} 0.75 ; 95 \% \mathrm{Cl}, 0.65- \\
0.85 ; \mathrm{P}<0.00 \mathrm{I} \text {, respectively for primary } \\
\text { and secondary outcomes) }\end{array}$ \\
\hline $\begin{array}{l}\text { DECLARE- } \\
\text { TIMI } 58 \\
(2019)^{12}\end{array}$ & $\begin{array}{l}17,190 \\
\text { Randomized, } \\
\text { double-blind, } \\
\text { multinational, } \\
\text { placebo-controlled, } \\
\text { phase } 3 \text { trial. } \\
\text { Median follow up } \\
4.2 \text { years }\end{array}$ & $\begin{array}{l}\text { Male or female } 40 \text { years of age or } \\
\text { older with type } 2 \text { diabetes, and } \\
\text { a creatinine clearance of } 60 \mathrm{~mL} \text { or } \\
\text { more per minute. }\end{array}$ & $\begin{array}{l}\text { Primary safety outcome was MACE } \\
\text { (defined as cardiovascular death, } \\
\text { myocardial infarction, or ischemic } \\
\text { stroke). Two Primary efficacy } \\
\text { outcomes were MACE and } \\
\text { a composite of cardiovascular death or } \\
\text { hospitalization for heart failure } \\
\text { Secondary efficacy outcomes: } \\
\text { Renal composite outcome, defined as } \\
\text { a sustained decrease of } 40 \% \text { or more in } \\
\text { estimated glomerular filtration rate, new } \\
\text { end-stage renal disease, or death from } \\
\text { renal or cardiovascular cause. } \\
\text { Death from any cause }\end{array}$ & $\begin{array}{l}\text { Dapagliflozin met with primary safety } \\
\text { efficacy outcome (upper boundary of the } \\
95 \% \mathrm{Cl},<1.3 ; \mathrm{P}<0.00 \mathrm{I} \text { for noninferiority). } \\
\text { It did not result in a lower rate of MACE } \\
\text { than placebo ( } 8.8 \% \text { and } 9.4 \% \text { in the two } \\
\text { groups, respectively; hazard ratio, } 0.93 ; \\
95 \% \mathrm{Cl}, 0.84-1.03 ; \mathrm{P}=0.17 \text { ); It did } \\
\text { however, result in a lower rate of } \\
\text { cardiovascular death or hospitalization for } \\
\text { heart failure than placebo ( } 4.9 \% \text { vs } 5.8 \% \text {; } \\
\text { hazard ratio, } 0.83 ; 95 \% \mathrm{Cl}, 0.73-0.95 ; \mathrm{P}= \\
0.005 \text { ). } \\
\text { There was no statistically significant } \\
\text { difference between the groups with } \\
\text { regards to the secondary efficacy } \\
\text { outcomes. }\end{array}$ \\
\hline $\begin{array}{l}\text { DEFINE- HF } \\
(2019)^{13}\end{array}$ & $\begin{array}{l}263 \\
\text { Randomized, } \\
\text { double-blind, } \\
\text { placebo controlled, } \\
\text { investigator- } \\
\text { initiated multi- } \\
\text { center trial } \\
\text { Follow up } 12 \\
\text { weeks }\end{array}$ & $\begin{array}{l}\text { Adult ambulatory patients with or } \\
\text { without T2DM, established HF for at } \\
\text { least } 16 \text { weeks and NYHA II-III HF }\end{array}$ & $\begin{array}{l}\text { Primary end points: } \\
\text { Average of 6- and I2-week mean NT- } \\
\text { proBNP. } \\
\text { Composite of the proportion of patients } \\
\text { that achieved a meaningful improvement } \\
\text { in health status ( } \geq 5 \text {-point increase in } \\
\text { average of 6- and I2-week KCCQ-OS) } \\
\text { or NT-proBNP ( } \geq 20 \% \text { decrease in } \\
\text { average of 6- and I } 2 \text {-week NT-proBNP). } \\
\text { Secondary end points included } \\
\text { proportion of patients with meaningful } \\
\text { change in KCCQ, and NT-proBNP at } \\
\text { each time point, mean BNP and } \\
\text { proportion of patients with meaningful } \\
\text { change in BNP, functional status based } \\
\text { on } 6 \text {-minute walk test, change in weight, } \\
\text { systolic blood pressure and HbAIc }\end{array}$ & 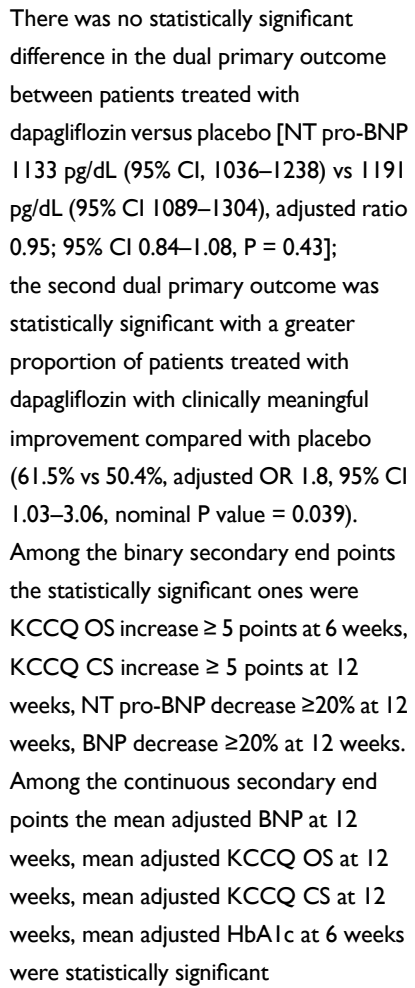 \\
\hline
\end{tabular}

(Continued) 
Table 2 (Continued).

\begin{tabular}{|c|c|c|c|c|}
\hline $\begin{array}{l}\text { Trial Name } \\
\text { (Year of } \\
\text { Publication) }\end{array}$ & $\begin{array}{l}\text { Sample Size, } \\
\text { Trial Design and } \\
\text { Follow-Up } \\
\text { Period }\end{array}$ & Sample Population & Primary \& Secondary Outcomes & Results \\
\hline $\begin{array}{l}\text { IDDIA } \\
(2020)^{26}\end{array}$ & $\begin{array}{l}60 \\
\text { Randomized, } \\
\text { double-blind, } \\
\text { placebo-controlled } \\
\text { trial } \\
\text { Follow up } 24 \\
\text { weeks }\end{array}$ & $\begin{array}{l}\text { Patients with T2DM and HbAIc of } \\
7.0 \% \text { to } 10.0 \% \text { accompanied by LV } \\
\text { diastolic dysfunction at least grade I } \\
\text { (relaxation abnormality) on resting } \\
\text { echocardiography }\end{array}$ & $\begin{array}{l}\text { Primary end point: } \\
\text { Change is LV diastolic reserve at } 24 \\
\text { weeks from baseline as assessed by } \\
\text { diastolic stress echocardiography } \\
\text { Secondary end points: } \\
\text { Changes at } 24 \text { weeks in LV diastolic } \\
\text { parameters at rest and during exercise, LV } \\
\text { mass index, and left atrial volume index }\end{array}$ & $\begin{array}{l}\text { The patients in dapagliflozin group had } \\
\text { significantly improved DR25W }(0.88 \\
\pm 1.24 \mathrm{~cm} / \mathrm{s} \text { versus }-0.52 \pm 1.53 \mathrm{~cm} / \mathrm{s} ; \mathrm{P}= \\
0.00 \mathrm{I}) \text { and DR50W }(0.59 \pm 1.47 \mathrm{~cm} / \mathrm{s} \\
\text { versus }-0.58 \pm 1.63 \mathrm{~cm} / \mathrm{s} ; \mathrm{P}=0.035) \\
\text { compared with those in the placebo } \\
\text { group at } 24 \text { weeks. }\end{array}$ \\
\hline
\end{tabular}

Abbreviations: DAPA-HF, Study to Evaluate the Effect of Dapagliflozin on the Incidence of Worsening Heart Failure or Cardiovascular Death in Patients With Chronic Heart Failure; DECLARE-TIMI 58, Dapagliflozin and Cardiovascular Outcomes in Type 2 Diabetes; DEFINE-HF, Dapagliflozin Effect on Symptoms and Biomarkers in Patients With Heart Failure With Reduced Ejection Fraction; IDDIA, Randomized, Controlled Trial to Evaluate the Effect of Dapagliflozin on Left Ventricular Diastolic Function in Patients With Type 2 Diabetes Mellitus; HFrEF, Heart failure with reduced ejection fraction; NYHA, New York Heart Association; LVEF, left ventricular ejection fraction; NTproBNP, N-terminal pro b-type natriuretic peptide; eGFR, estimated glomerular filtration rate; CKD-EPI, Chronic Kidney Disease Epidemiology Collaboration; GDMT, guideline-directed medical therapy; MACE, major adverse cardiovascular events; T2DM, Type 2 Diabetes Mellitus; HF, heart failure; KCCQ, Kansas City Cardiomyopathy Questionnaire; KCCQ-OS, Kansas City Cardiomyopathy Questionnaire Overall Summary Score; HbAIc, Glycated hemoglobin; KCCQ CS, Kansas City Cardiomyopathy Questionnaire Clinical Summary Score; BNP, B-type natriuretic peptide; LV, left ventricular; DR25W, Diastolic reserve at 25 Watts; DR50W, Diastolic reserve at 50 Watts.

ongoing - the DETERMINE-Preserved trial (NCT03877224) and the DELIVER trial (NCT03619213) that will help shed light on the role of the drug in this largely under-treated patient population. In the light of a very recent press release indicating beneficial effects of empagliflozin in HFpEF patients, the likelihood of similar results with dapagliflozin is higher due to significant overlap in the mechanism of both the drugs (NCT03057951).

Furthermore, there are numerous trials that are aimed at providing a mechanistic explanation for the benefit seen with dapagliflozin in terms of cardiac remodeling and change in biomarkers. Cardiac remodeling measured with parameters such as left atrial anatomy, functionality and left ventricular distensibility (on echocardiography) and myocardial perfusion reserve index (on cardiac magnetic resonance imaging) is one way of understanding these mechanisms. The REFORM trial studied the left ventricular end systolic volume on cardiac magnetic resonance imaging (MRI) as an endpoint in HF patients with DM treated with dapagliflozin. Unfortunately, at the end of the follow-up period of 1 year, no significant difference was noted. $^{35}$ In another MRI-based study, treatment with dapagliflozin showed a significant reduction in left ventricular mass after 12 months, compared with the placebo group. ${ }^{36}$ In a small study in Japan, it was shown that treatment with dapagliflozin significantly improved mitral inflow $\mathrm{E}$ and mitral annular e' velocities (E/e') after 6 months in diabetics with established $\mathrm{HF}^{37}$ The IDDIA trial further showed improvement in left ventricular diastolic dysfunction (assessed on diastolic stress echocardiography) in type II diabetics with LVEF $>50 \%{ }^{38}$ With only small-scale studies evaluating the mechanism of remodeling, our understanding remains limited and further research is required in this area. The ongoing STADIA trial is also recruiting patients with $\mathrm{HFpEF}$ to study the change in left ventricular stiffness measured as extracellular volume change (on cardiac magnetic resonance) and changes in $\mathrm{E} / \mathrm{e} / \mathrm{LV}$ end-diastolic volume index (on echocardiography). ${ }^{39}$

\section{Dapagliflozin in Guidelines}

The DAPA-HF trial illustrated the benefits of SGLT2 inhibitors (specifically dapagliflozin) in treating established HF, by showing that dapagliflozin not only significantly reduced the risk of worsening $\mathrm{HF}$ or the risk of $\mathrm{CV}$ death, but also improved the symptoms of HF in 4744 patients with HFrEF. ${ }^{5}$ The ACC Clinical Pathway in HF guidelines currently recommend dapagliflozin $10 \mathrm{mg}$ daily, for reducing the risk of HF hospitalizations in adults with DM and established CV disease (or having multiple risk factors), and for reducing the risk of hospitalizations and $\mathrm{CV}$ death in patients with HFrEF. ${ }^{6}$ The use of the medication is not recommended for glycemic control in patients with eGFR $<45 \mathrm{~mL} / \mathrm{min} / 1.73 \mathrm{~m}^{2}$. Other contraindications include hypersensitivity, pregnancy/breastfeeding, need for dialysis, and end stage renal disease. ${ }^{6}$ 

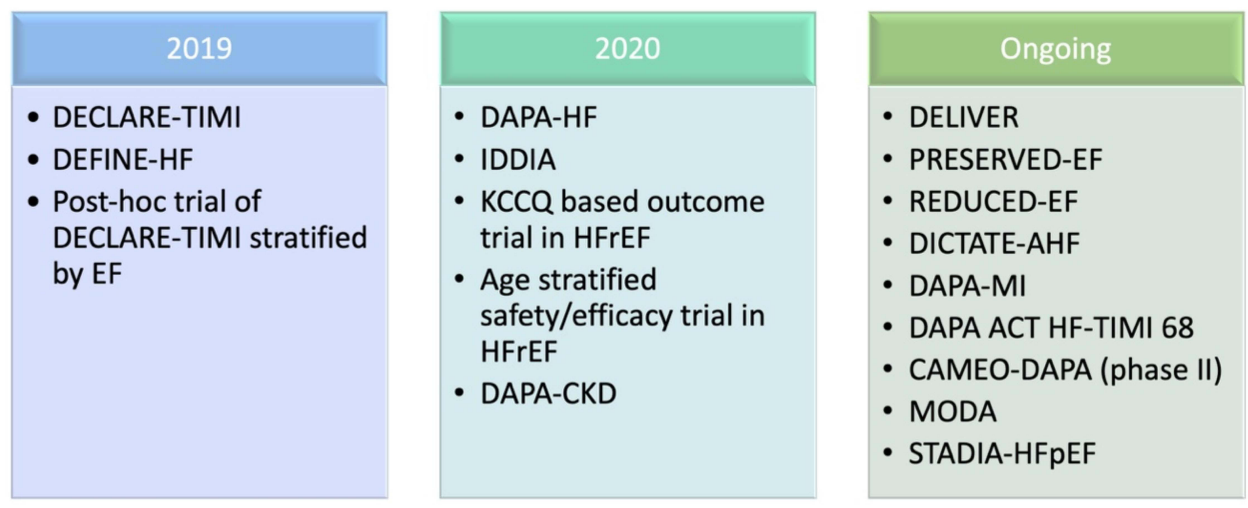

Figure I Chronology of key trials evaluating dapagliflozin.

Abbreviations: EF, ejection fraction; KCCQ, Kansas City Cardiomyopathy Questionnaire; HFrEF, heart failure with reduced ejection fraction.

In October 2020, the Heart Failure Association of the European Society of Cardiology (ESC) released updated recommendations for the utilization of SGLT2 inhibitors in HF patients, based on the new clinical trial evidence. Dapagliflozin is recommended for prevention of HHF in patients with $\mathrm{DM}$ and established $\mathrm{CV}$ disease or at high risk for CV disease (similar to the ACC guidelines). ${ }^{40,41}$ The use of dapagliflozin is also recommended for reducing the combined risk of $\mathrm{HHF}$ and $\mathrm{CV}$ death in symptomatic HFrEF patients, already receiving GDMT, regardless of the presence of DM. $^{40,41}$

\section{Conclusion}

Dapagliflozin is the latest addition to the toolbox of therapies used to manage HF and has garnered substantial interest in the last year and a half, as represented in Figure 1. The initial evidence supporting use of dapagliflozin as an add-on therapy for patients with HFrEF to significantly reduce the incidence of CV endpoints such as CV death and HHF was extrapolated from trials based on evaluation of the drug for primary treatment of DM. However, in recent times, the drug has been studied in dedicated HF clinical trials to reveal clinically significant utility as an add-on to GDMT in patients with HFrEF, irrespective of DM status. Another huge step forward is the result of the DAPA-CKD trial that prove the safety of dapagliflozin in patients with eGFR as low as $25 \mathrm{~mL} / \mathrm{min} /$ $1.73 \mathrm{~m}^{2}$, enabling clinicians to target a population that cannot be managed with traditional therapy. Initial data also indicate cost-related benefits of adding dapagliflozin to GDMT, when compared with the overall cost of HF management including hospitalization. Professional societies such as ACC and ESC endorse the addition of dapagliflozin in patients with an established diagnosis of HFrEF (with or without DM) to prevent $\mathrm{HHF}$ and reduce CV mortality. The ACC Clinical Pathway in
$\mathrm{HF}$ also recommends the use of the drug in patients with DM at risk for $\mathrm{CV}$ disease. This article is the first article that we know of that summarizes the current and ongoing evidence on use of dapagliflozin. The exact indication of the drug is yet to be established as newer evidence will possibly expand its use in HFpEF and acutely decompensated HF, which were outside the scope of this article.

\section{Funding}

There is no funding to report.

\section{Disclosure}

Dr Fonarow's disclosures include consulting for Abbott, Amgen, AstraZeneca, Bayer, Edwards, Janssen, Medtronic, Merck, and Novartis. The authors reported no other potential conflicts of interest for this work.

\section{References}

1. Virani SS, Alonso A, Benjamin EJ, et al. Heart disease and stroke statistics-2020 update: a report from the American Heart Association. Circulation. 2020;141(9):e139-e596. doi:10.1161/CIR.000000000 0000757

2. Shah KS, Xu H, Matsouaka RA, et al. Heart failure with preserved, borderline, and reduced ejection fraction: 5-year outcomes. $J$ Am Coll Cardiol. 2017;70(20):2476-2486. doi:10.1016/j.jacc.2017.08.074

3. Greene SJ, Butler J, Albert NM, et al. Medical therapy for heart failure with reduced ejection fraction: the CHAMP-HF registry. $J$ Am Coll Cardiol. 2018;72(4):351-366. doi:10.1016/j.jacc.2018.04.070

4. Packer M, Anker SD, Butler J, et al. Cardiovascular and renal outcomes with empagliflozin in heart failure. $N$ Engl $J$ Med. 2020;383:1413-1424. doi:10.1056/NEJMoa2022190

5. McMurray JJV, Solomon SD, Inzucchi SE, et al. Dapagliflozin in patients with heart failure and reduced ejection fraction. $N$ Engl J Med. 2019;381(21):1995-2008. doi:10.1056/NEJMoa1911303

6. Das SR, Everett BM, Birtcher KK, et al. 2020 expert consensus decision pathway on novel therapies for cardiovascular risk reduction in patients with type 2 diabetes: a report of the American College of Cardiology Solution Set Oversight Committee. J Am Coll Cardiol. 2020;76(9):1117-1145. doi:10.1016/j.jacc.2020.05.037 
7. Riddle MC. Effects of intensive glucose lowering in the management of patients with type 2 diabetes mellitus in the Action to Control Cardiovascular Risk in Diabetes (ACCORD) trial. Circulation. 2010;122(8):844-846. doi:10.1161/CIRCULATIONAHA.110.96 0138

8. Vallon V, Thomson SC. Targeting renal glucose reabsorption to treat hyperglycaemia: the pleiotropic effects of SGLT2 inhibition. Diabetologia. 2017;60(2):215-225. doi:10.1007/s00125-016-4157-3

9. Cowie MR, Fisher M. SGLT2 inhibitors: mechanisms of cardiovascular benefit beyond glycaemic control. Nat Rev Cardiol. 2020;17 (12):761-772. doi:10.1038/s41569-020-0406-8

10. Petrie MC, Verma S, Docherty KF, et al. Effect of dapagliflozin on worsening heart failure and cardiovascular death in patients with heart failure with and without diabetes. JAMA. 2020;323 (14):1353-1368. doi:10.1001/jama.2020.1906

11. Adverse effect profile of dapagliflozin. Available from: https://www. farxiga-hcp.com/cardiology/hfref/study-design. Accessed July 21, 2021.

12. Verma S, McMurray JJV. SGLT2 inhibitors and mechanisms of cardiovascular benefit: a state-of-the-art review. Diabetologia. 2018;61(10):2108-2117. doi:10.1007/s00125-018-4670-7

13. Hou Y-C, Zheng C-M, Yen T-H, Lu K-C. Molecular mechanisms of SGLT2 inhibitor on cardiorenal protection. Int J Mol Sci. 2020;21 (21):7833. doi:10.3390/ijms21217833

14. Uthman L, Baartscheer A, Bleijlevens B, et al. Class effects of SGLT2 inhibitors in mouse cardiomyocytes and hearts: inhibition of $\mathrm{Na}+\mathrm{H}+$ exchanger, lowering of cytosolic $\mathrm{Na}+$ and vasodilation. Diabetologia. 2018;61(3):722-726. doi:10.1007/s00125-017-4509-7

15. Cherney DZI, Perkins BA, Soleymanlou N, et al. Renal hemodynamic effect of sodium-glucose cotransporter 2 inhibition in patients with type 1 diabetes mellitus. Circulation. 2014;129(5):587-597. doi:10.1161/CIRCULATIONAHA.113.005081

16. Vallon V, Blantz RC, Thomson S. Glomerular hyperfiltration and the salt paradox in early [corrected] type 1 diabetes mellitus: a tubulo-centric view. J Am Soc Nephrol. 2003;14(2):530-537. doi:10.1097/01.asn.0000051700.07403.27

17. Ghosh RK, Ghosh GC, Gupta M, et al. Sodium glucose co-transporter 2 inhibitors and heart failure. Am J Cardiol. 2019;124(11):1790-1796. doi:10.1016/j.amjcard.2019.08.038

18. Wiviott SD, Raz I, Bonaca MP, et al. Dapagliflozin and cardiovascular outcomes in type 2 diabetes. $N$ Engl J Med. 2019;380 (4):347-357. doi:10.1056/NEJMoa1812389

19. Nassif ME, Windsor SL, Tang F, et al. Dapagliflozin effects on biomarkers, symptoms, and functional status in patients with heart failure with reduced ejection fraction: the DEFINE-HF trial. Circulation. 2019;140 (18):1463-1476. doi:10.1161/CIRCULATIONAHA.119.042929

20. Kosiborod MN, Jhund PS, Docherty KF, et al. Effects of dapagliflozin on symptoms, function, and quality of life in patients with heart failure and reduced ejection fraction: results from the DAPA-HF trial. Circulation. 2020;141(2):90-99. doi:10.1161/ CIRCULATIONAHA.119.044138

21. Shen L, Kristensen SL, Bengtsson O, et al. Dapagliflozin in HFrEF patients treated with mineralocorticoid receptor antagonists: an analysis of DAPA-HF. JACC Heart Fail. 2021;9:254-264. doi:10.1016/j. jchf.2020.11.009

22. Solomon SD, Jhund PS, Claggett BL, et al. Effect of dapagliflozin in patients with HFrEF treated with sacubitril/valsartan: the DAPA-HF trial. JACC Heart Fail. 2020;8(10):811-818. doi:10.1016/j.jchf.2020.04.008

23. Berg DD, Jhund PS, Docherty KF, et al. Time to clinical benefit of dapagliflozin and significance of prior heart failure hospitalization in patients with heart failure with reduced ejection fraction. JAMA Cardiol. 2021;6:499. doi:10.1001/jamacardio.2020.7585

24. Butt JH, Nicolau JC, Verma S, et al. Efficacy and safety of dapagliflozin according to aetiology in heart failure with reduced ejection fraction: insights from the DAPA-HF trial. Eur $J$ Heart Fail. 2021;23:601-613. doi:10.1002/ejhf.2124
25. Cai R-P, Xu Y-L, Su Q, Dini F. Dapagliflozin in patients with chronic heart failure: a systematic review and meta-analysis. Cardiol Res Pract. 2021;2021:6657380. doi:10.1155/2021/6657380

26. Chambergo-Michilot D, Tauma-Arrué A, Loli-Guevara S. Effects and safety of SGLT2 inhibitors compared to placebo in patients with heart failure: a systematic review and meta-analysis. Int $J$ Cardiol Heart Vasc. 2021;32:100690. doi:10.1016/j.ijcha.2020.100690

27. Zheng X-D, Qu Q, Jiang X-Y, Wang Z-Y, Tang C, Sun J-Y. Effects of dapagliflozin on cardiovascular events, death, and safety outcomes in patients with heart failure: a meta-analysis. Am J Cardiovasc Drugs. 2021;21(3):321-330. doi:10.1007/s40256-020-00441-x

28. Zannad F, Ferreira JP, Pocock SJ, et al. SGLT2 inhibitors in patients with heart failure with reduced ejection fraction: a meta-analysis of the EMPEROR-reduced and DAPA-HF trials. Lancet Lond Engl. 2020;396(10254):819-829. doi:10.1016/S0140-6736(20)31824-9

29. Heerspink HJL, Stefánsson BV, Correa-Rotter R, et al. Dapagliflozin in patients with chronic kidney disease. $N$ Engl J Med. 2020;383 (15):1436-1446. doi:10.1056/NEJMoa2024816

30. McEwan P, Morgan AR, Boyce R, et al. The cost-effectiveness of dapagliflozin in treating high-risk patients with type 2 diabetes mellitus: an economic evaluation using data from the DECLARE-TIMI 58 trial. Diabetes Obes Metab. 2021;23(4):1020-1029. doi:10.1111/dom.14308

31. Savira F, Wang BH, Kompa AR, et al. Cost-effectiveness of dapagliflozin in chronic heart failure: an analysis from the Australian healthcare perspective. Eur J Prev Cardiol. 2020;41:2047487320938272. doi:10.1177/2047487320938272.

32. Krittayaphong R, Permsuwan U. Cost-utility analysis of add-on dapagliflozin treatment in heart failure with reduced ejection fraction. Int $J$ Cardiol. 2021;322:183-190. doi:10.1016/j.ijcard.20 20.08.017

33. Isaza N, Calvachi P, Raber I, et al. Abstract 15981: cost-effectiveness of dapagliflozin in heart failure with reduced ejection fraction. Circulation. 2020;142(Suppl_3):A15981. doi:10.1161/circ.142.suppl_3.15981

34. Maltês S, Cunha GJL, Rocha BML, et al. Dapagliflozin in a real-world chronic heart failure population: how many are actually eligible? Cardiology. 2021;146(2):201-206. doi:10.1159/000512432

35. Singh JSS, Mordi IR, Vickneson K, et al. Dapagliflozin versus placebo on left ventricular remodeling in patients with diabetes and heart failure: the REFORM trial. Diabetes Care. 2020;43 (6):1356-1359. doi:10.2337/dc19-2187

36. Brown AJM, Gandy S, McCrimmon R, Houston JG, Struthers AD, Lang CC. A randomized controlled trial of dapagliflozin on left ventricular hypertrophy in people with type two diabetes: the DAPA-LVH trial. Eur Heart J. 2020;41(36):3421-3432. doi:10. 1093/eurheartj/ehaa419

37. Soga F, Tanaka H, Tatsumi K, et al. Impact of dapagliflozin on left ventricular diastolic function of patients with type 2 diabetic mellitus with chronic heart failure. Cardiovasc Diabetol. 2018;17(1):132. doi:10.1186/s12933-018-0775-z

38. Shim CY, Seo J, Cho I, et al. Randomized, controlled trial to evaluate the effect of dapagliflozin on left ventricular diastolic function in patients with type 2 diabetes mellitus: the IDDIA trial. Circulation. 2021;143 (5):510-512. doi:10.1161/CIRCULATIONAHA.120.051992

39. Scheffer M, Driessen-Waaijer A, Hamdani N, et al. Stratified treatment of heart failure with preserved ejection fraction: rationale and design of the STADIA-HFpEF trial. ESC Heart Fail. 2020;7: 4478-4487. doi:10.1002/ehf2.13055

40. Seferović PM, Fragasso G, Petrie M, et al. Heart Failure Association of the European Society of Cardiology update on sodium-glucose co-transporter 2 inhibitors in heart failure. Eur J Heart Fail. 2020;22 (11):1984-1986. doi:10.1002/ejhf.2026

41. Seferović PM, Coats AJS, Ponikowski P, et al. European Society of Cardiology/Heart Failure Association position paper on the role and safety of new glucose-lowering drugs in patients with heart failure. Eur J Heart Fail. 2020;22(2):196-213. doi:10.1002/ejhf.1673 


\section{Publish your work in this journal}

Therapeutics and Clinical Risk Management is an international, peerreviewed journal of clinical therapeutics and risk management, focusing on concise rapid reporting of clinical studies in all therapeutic areas, outcomes, safety, and programs for the effective, safe, and sustained use of medicines. This journal is indexed on PubMed Central, CAS,
EMBase, Scopus and the Elsevier Bibliographic databases. The manuscript management system is completely online and includes a very quick and fair peer-review system, which is all easy to use Visit http://www.dovepress.com/testimonials.php to read real quotes from published authors.

Submit your manuscript here: https://www.dovepress.com/therapeutics-and-clinical-risk-management-journal 